\title{
An Integrated Power Pack of Dye-Sensitized Solar Cell and Li Battery Based on Double-Sided $\mathrm{TiO}_{2}$ Nanotube Arrays
}

\author{
Wenxi Guo, ${ }^{\dagger, \ddagger} \perp$ Xinyu Xue, ${ }^{\dagger, \S, \perp}$ Sihong Wang, ${ }^{\dagger}$ Changjian Lin, ${ }^{\ddagger}$ and Zhong Lin Wang*, ${ }^{\dagger}, \|$ \\ ${ }^{\dagger}$ School of Material Science and Engineering, Georgia Institute of Technology, Georgia 30332, United States \\ ${ }^{\ddagger}$ State Key Laboratory of Physical Chemistry of Solid Surfaces, College of Chemistry and Chemical Engineering, Xiamen University, \\ Xiamen 361005, China \\ ${ }^{\S}$ College of Sciences, Northeastern University, Shenyang 110004, China \\ "Beijing Institute of Nanoenergy and Nanosystems, Chinese Academy of Sciences, Beijing, China
}

\section{Supporting Information}

ABSTRACT: We present a new approach to fabricate an integrated power pack by hybridizing energy harvest and storage processes. This power pack incorporates a series-wound dyesensitized solar cell (DSSC) and a lithium ion battery (LIB) on the same $\mathrm{Ti}$ foil that has double-sided $\mathrm{TiO}_{2}$ nanotube (NTs) arrays. The solar cell part is made of two different cosensitized tandem solar cells based on $\mathrm{TiO}_{2}$ nanorod arrays (NRs) and NTs, respectively, which provide an open-circuit voltage of $3.39 \mathrm{~V}$ and a short-circuit current density of $1.01 \mathrm{~mA} / \mathrm{cm}^{2}$. The power pack can be charged to about $3 \mathrm{~V}$ in about $8 \mathrm{~min}$, and the discharge capacity is about $38.89 \mu \mathrm{Ah}$ under the discharge density of 100 $\mu \mathrm{A}$. The total energy conversion and storage efficiency for this system is $0.82 \%$. Such an integrated power pack could serve as a

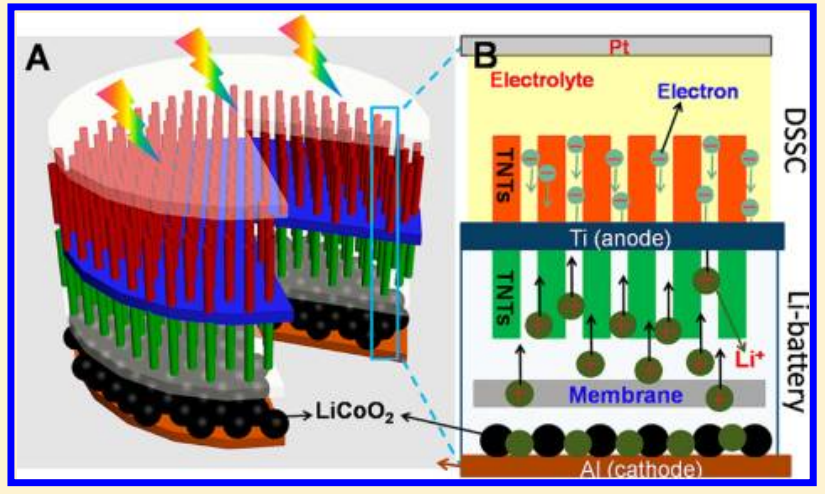
power source for mobile electronics.

KEYWORDS: Solar cell, lithium ion battery, $\mathrm{TiO}_{2}$ nanotubes, mobile energy

$\mathrm{R}$ ecently, nanostructures have been widely used in energy harvesting devices, such as dye-sensitized solar cells (DSSCs), nanogenerators, and fuel cells, due to their high efficiency and lightweight. ${ }^{1-9}$ Among them, nanostructurebased DSSCs are likely to be low-cost, high efficiency, and simple in preparation, which is promising as a renewable energy resource for sustainable development of the future. ${ }^{1,4,5,10}$ At the same time, nanostructures have been used in energy storage fields, such as lithium ion batteries (LIBs), due to their highenergy density and long cycle life. ${ }^{11-14}$ These energy harvesting and storage approaches are developed as independent technologies but usually are used together as a power system. Traditionally, the power pack is based on a silicon solar panel and a solid-state lithium battery as the two independent parts, which is large, heavy, and inflexible. Therefore, in order to satisfy the special needs in some fields, hybridizing energy harvesting and storage units as an integrated power pack based on same nanostructured substrates may be an effective way to obtain a small size, lightweight, and high-density energy system.

In this paper, we report a new integrated power system of DSSC and LIB to hybridize energy harvest and storage processes based on double-sided $\mathrm{TiO}_{2} \mathrm{NTs}$ grown on the same substrate. Double-sided $\mathrm{TiO}_{2} \mathrm{NTs}$ not only provide larger electrode area for DSSCs and LIBs but also can improve the electron transport properties of DSSCs and avoid irregular expansion when the insertion/removal of lithium along a specific orientation in anode material. ${ }^{11,15}$ Compared with other integrated solar power supplies, ${ }^{16,17}$ double-sided $\mathrm{TiO}_{2}$ NTs with large area can be prepared by a simple, cost-effective, and controllable electrochemical process. Taking the advantages of the titanium $(\mathrm{Ti})$ sheet substrate, the integrated power pack can be flexible and directly harvest and store energy by the electron conduction of the substrate. By using this hybird structure, the voltage of the power pack can be charged to $\sim 3 \mathrm{~V}$ in $\sim 8 \mathrm{~min}$, and the discharge capacity is $\sim 38.89 \mu \mathrm{Ah}$ under the discharge density of $100 \mu \mathrm{A}$, a total of $0.82 \%$ energy conversion and storage efficiency has been demonstrated.

Design of the Integrated Power Pack. The structures and working principle of the integrated power pack are based on a light-electrochemical process, as shown in Figure 1, which is accomplished by two separate processes. This power pack is based on a Ti foil with $\mathrm{TiO}_{2}$ NTs growing on both sides. The upper part is the DSSCs fabricated using $\mathrm{TiO}_{2} \mathrm{NT}$ arrays as the electron collector with largely increased surface area. The lower part is the $\mathrm{TiO}_{2} \mathrm{NT}$-based LIB for storing the generated energy by the DSSCs. The DSSCs and LIBs share the same Ti

Received: February 21, 2012

Revised: April 20, 2012 


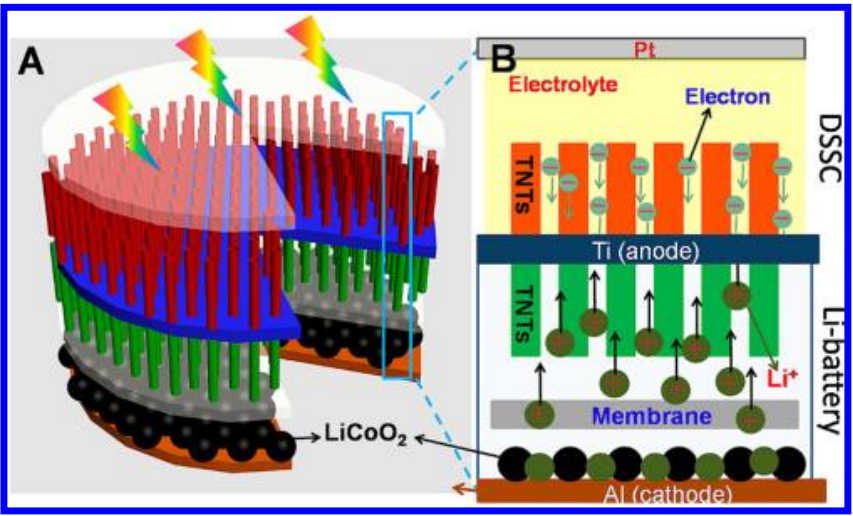

Figure 1. Design and principle of an integrated power pack system based on double-sided $\mathrm{TiO}_{2}$ nanotube arrays. (A) $\mathrm{TiO}_{2}$ nanotube arrays grown on the $\mathrm{Ti}$ foil substrate by anodization in fluoric ethylene glycol solution. The top segment of the Ti foil is tandem DSSCs which are utilized to harvest sunlight from environment, and the bottom segment is a typical lithium ion battery which is used to store energy converted from DSSCs. (B) Detailed structure and working principle of the integrated power pack system.

substrate. When sun light irradiates on the DSSCs, the generated electrons will be injected into the conduction band of $\mathrm{TiO}_{2}$ NTs from dye molecules and transported along the $\mathrm{Ti}$ foil to the anode of $\mathrm{LIB}\left(\mathrm{TiO}_{2}\right)$, while the generated holes accumulate at the $\mathrm{Pt}$ electrode. The LIB part is under a charging condition. The electron donation output from the DSSCs and lithium ions will react on at the anodes and will induce the following chemical process as $\mathrm{TiO}_{2}+x \mathrm{Li}^{+}+x \mathrm{e}^{-} \rightarrow$ $\mathrm{Li}_{x} \mathrm{TiO}_{2}{ }^{18}$ At the same time, the reaction of the cathode $\mathrm{LiCoO}_{2} \rightarrow \mathrm{Li}_{1-x} \mathrm{CoO}_{2}+x \mathrm{Li}^{+}+x \mathrm{e}^{-}$releases free electrons that will flow to the counter electrode of the DSSC through an external circuit to combine with the holes in the Pt electrode. This is the entire process for charge generation, separation, and storage.

Material Preparations. $\mathrm{TiO}_{2}$ NTs on both sides of Ti foil: The $\mathrm{TiO}_{2}$ NTs were fabricated by electrochemically anodizing Ti foil ( $0.05 \mathrm{~mm}$ thick, $99.6 \%$ purity; Alfa Aesar) in ethylene glycol solution containing 0.3 wt $\%$ of $\mathrm{NH}_{4} \mathrm{~F}$ and 2 vol\% of $\mathrm{H}_{2} \mathrm{O}$ with $\mathrm{Pt}$ as a counter electrode. ${ }^{19}$ Before anodization, both sides of the Ti foil were ultrasonically cleaned in acetone, water, and ethanol consecutively and then dried in air. The prepared $\mathrm{Ti}$ foil was first anodized at $50 \mathrm{~V}$ for $6 \mathrm{~h}$. The resulting nanotube films on both sides of the foils were then removed by ultrasonication in acetone for a few seconds, leaving hexagonlike footprints on both surfaces of the foils. A second anodization was then performed under the same condition for $2 \mathrm{~h}$ to produce double-sided well-aligned $\mathrm{TiO}_{2} \mathrm{NTs}$ with a layer of mesopores on the top. ${ }^{20}$ Subsequently, the anodized NTs on both sides of Ti foils were annealed at $450{ }^{\circ} \mathrm{C}$ for $2 \mathrm{~h}$ in air to form anatase crystal phase with relatively high crystal purity.

$\mathrm{TiO}_{2}$ NRs: The $\mathrm{TiO}_{2}$ NRs were synthetized by using the hydrothermal method as previously reported by Liu and Aydil. $^{21} 0.4 \mathrm{~mL}$ of titanium butoxide was added into the mixture containing $9 \mathrm{~mL}$ of deionized water and $9 \mathrm{~mL}$ of concentrated hydrochloric acid (36\%-38\% by weight) slowly. After stirring for $30 \mathrm{~min}$, the as-prepared mixture was put into a $25 \mathrm{~mL}$ Teflon-lined stainless steel autoclave. Four pieces of FTO glass were placed at an angle against the wall of the Teflon, linear with the conducting side facing down. The hydrothermal synthesis was conducted at $190{ }^{\circ} \mathrm{C}$ for $1.5-3 \mathrm{~h}$ in an electric oven.

The morphology and microstructure of the $\mathrm{TiO}_{2}$ nanostuctures were examined by a scanning electron microscope (LEO 1530 SEM), and transmission electron microscopy (TEM, Hitachi HF2000 and JEOL 4000EX). Phase identification of $\mathrm{TiO}_{2}$ was conducted by X-ray diffraction (X'Pert PRO, PANalytical).

Figure $2 \mathrm{~A}-\mathrm{C}$ is SEM images of $\mathrm{TiO}_{2} \mathrm{NT}$ s obtained after the two-step anodization on both sides of the Ti foil, showing their

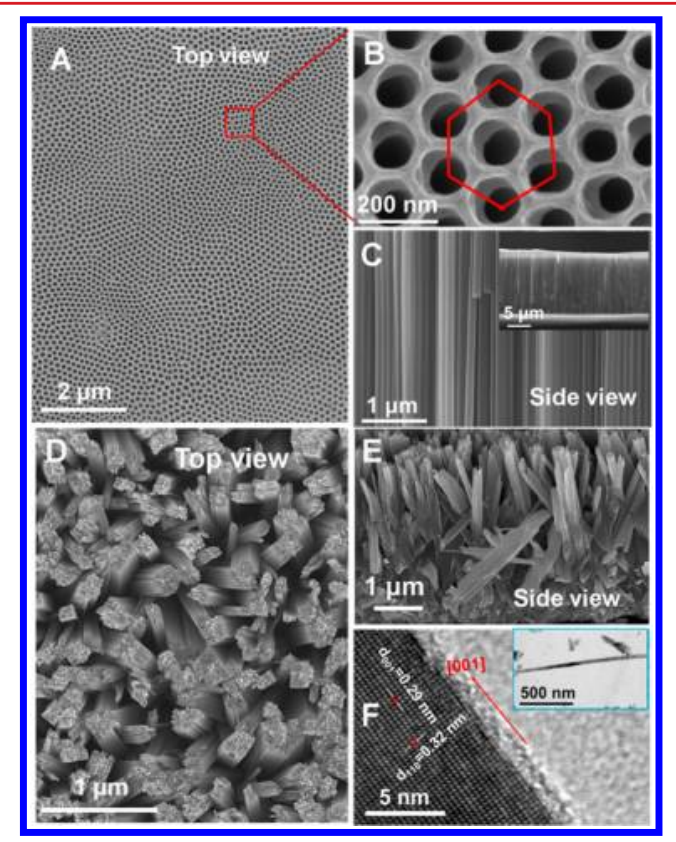

Figure 2. SEM images of a vertically oriented two-step anodized $\mathrm{TiO}_{2}$ nanotube array fabricated on $\mathrm{Ti}$ foil at $50 \mathrm{~V}$ for $3 \mathrm{~h}$ : $(\mathrm{A}, \mathrm{B})$ top-view images and (C) cross-sectional SEM images of the same arrays, mechanically fractured; inset shows magnified view. SEM and TEM images of $\mathrm{TiO}_{2}$ nanorod arrays grown on the FTO-coated glass at 190 ${ }^{\circ} \mathrm{C}$ for $3 \mathrm{~h}$ : (D) top-view and (E) cross-sectional view of the same arrays. (F) HRTEM images of a nanorod; insets are low-magnification images.

typical morphology and structures. From Figure 2A, it can be observed that uniformly aligned $\mathrm{TiO}_{2}$ NTs with similar structures on the top are obtained after a two-step anodization. From the enlarged view of the top of $\mathrm{TiO}_{2} \mathrm{NTs}$, as shown in the Figure $2 \mathrm{~B}$, it can be seen that every single nanotube is surrounded by six NTs that form a hexagon (labeled by red line). ${ }^{22}$ Cross-sectional view in Figure $2 \mathrm{C}$ shows that the length of the $\mathrm{TiO}_{2}$ NTs is about $15 \mu \mathrm{m}$. The X-ray diffraction (XRD) pattern of the $\mathrm{TiO}_{2}$ NTs is shown in Figure S1 (Supporting Information). All of the diffraction peaks can be readily indexed to anatase $\mathrm{TiO}_{2}$. An idealized nanotubular structure with relatively high crystal purity has been obtained.

The SEM and TEM images of $\mathrm{TiO}_{2}$ NRs obtained by hydrothermal treatment are shown in the Figure 2D-F. From Figure 2D, the entire surface of the FTO substrate is uniformly covered by $\mathrm{TiO}_{2}$ NRs that are tetragonal in shape with square top facets. A cross-sectional view of $\mathrm{TiO}_{2} \mathrm{NRs}$ is shown in Figure $2 \mathrm{~F}$, where the diameter of the NRs is $\sim 150 \mathrm{~nm}$ and the lengths are $\sim 3.5 \mu \mathrm{m}$. The phase and crystal structure of the $\mathrm{TiO}_{2} \mathrm{NRs}$ is confirmed with TEM observation, as shown in Figure 2E. The distance between lattice fringes is 0.32 and 0.29 $\mathrm{nm}$, respectively, which can be assigned to (110) and (001) of 
the rutile $\mathrm{TiO}_{2}$ phase. The $\mathrm{TiO}_{2} \mathrm{NRs}$ are grown along [001] axis. The XRD pattern of $\mathrm{TiO}_{2}$ NRs is shown in Figure S2 (Supporting Information). All of the diffraction peaks can be indexed to rutile $\mathrm{TiO}_{2}$ with relatively high crystal purity.

Assembly of Tandem Solar Cell Part. In order to provide enough high voltage for charging the LIB part with solar cell part, three tandem solar cells (SC I, 2SC II) are introduced, as shown in Figure 3A. Every single tandem cell is composed of

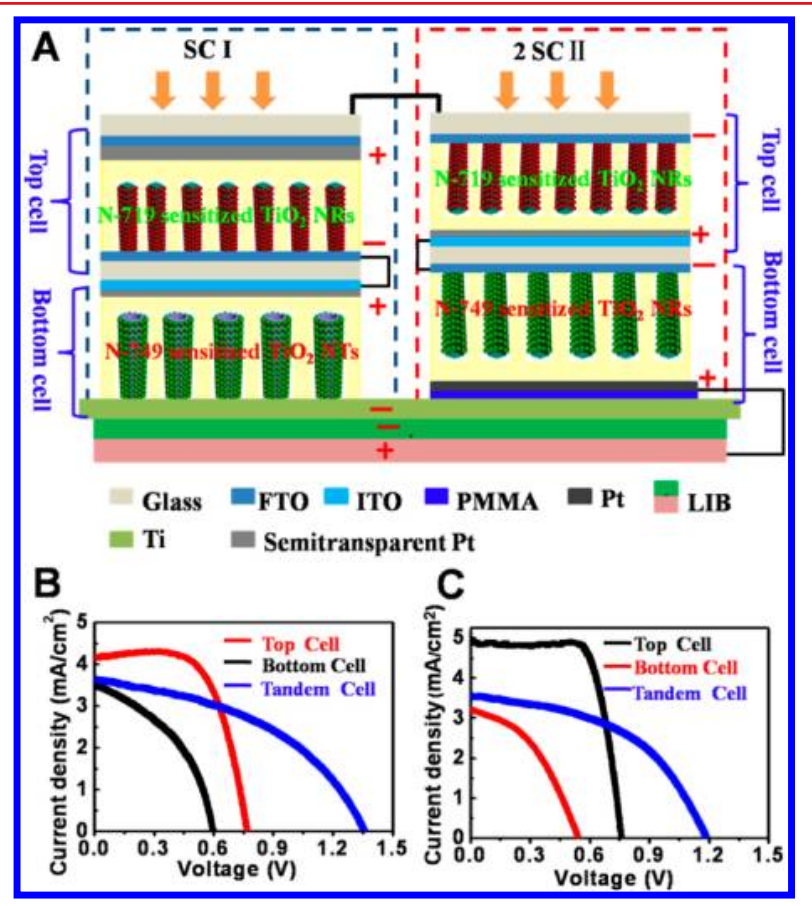

Figure 3. (A) Scheme represents the detailed structures and connections of cosensitized SC I and SC II. For the SC I, the topcell is $\mathrm{TiO}_{2}$ NRs based N-719 sensitized solar cell, while the bottom cell is $\mathrm{TiO}_{2}$ NTs based N-749 sensitized solar cell. For the SC II, topcell is $\mathrm{TiO}_{2}$ NRs based N-719 sensitized solar cell, and bottom cell is $\mathrm{TiO}_{2}$ NRs based N-749 sensitized solar cell. (C) and (D) are the corresponding $J-V$ currents of SC I and SC II.

two series-wound DSSCs which are named top and bottom cells. The top cell is sensitized by dye N-719, while the bottom cell is sensitized by dye N-749. Such a design absorbs the full wavelength spectrum of the solar by using two different types of dyes. When sun light irradiates on the cells, different wavelengths light will be absorbed by different dyes. The absorption spectra of the N-719 and N-749 dyes are shown in the Figure S3, Supporting Information. It is clear that N-719 mainly harvested the short-wavelength light $(400-550 \mathrm{~nm})$, and N-749 is responsible for absorbing in the longerwavelength region $(600-800 \mathrm{~nm})$.

For the SC I, as shown in the Figure 3A, the photoanode of the top cell was based on $\mathrm{TiO}_{2} \mathrm{NRs}$ that were sensitized by a $0.3 \mathrm{mM}$ cisbis(isothiocyanato)bis(2,2'-bipyridyl-4,4'-dicarboxylato)-ruthenium(II)bis-tetrabutylammonim dye (N-719 as received from Solaronix) solution in dry ethanol for $24 \mathrm{~h}$. The semitransparent counter electrode of the top cell was prepared by placing a drop of $\mathrm{H}_{2} \mathrm{PtCl}_{6}$ solution $(4 \mathrm{mM}$ in ethanol) on a FTO plate and heating at $400 \circ \mathrm{O}$ for $15 \mathrm{~min}$. The photoanode of the bottom cell was based on the $\mathrm{TiO}_{2} \mathrm{NTs}$ grown on the upper part of the Ti foil which were sensitized by a $0.3 \mathrm{mM}$ cis-bis(isothiocyanato)bis(2,2-bipyridyl-4,4-dicarboxylato)-ruthenium(II)bis-tetrabutylammonium dye (N-749 as received from Solaronix) solution in dry ethanol for $24 \mathrm{~h}$. The counter electrodes of the bottom cell are also semitransparent and share the same substrate with the photoanode of front cell: First, a thin layer of ITO was sputtered on the other side of the front cell photoanode, and then a drop of $\mathrm{H}_{2} \mathrm{PtCl}_{6}$ solution (4 $\mathrm{mM}$ in ethanol) was placed on the ITO layer and heated at 400 oC for $15 \mathrm{~min}$. The dye-adsorbed $\mathrm{TiO}_{2}$ electrode and the platinum counter electrode were assembled into a sealed sandwich-type cell using a liquid electrolyte comprising of 0.5 $\mathrm{M} \mathrm{LiI}, 50 \mathrm{mM} \mathrm{I}_{2}$, and $0.5 \mathrm{M}$ 4-tertbutylpyridine in 3methoxypropionitrile (Fluka). The tandem cell (as shown in Figure 3A) was prepared by placing the N-749 sensitized NTs based DSSC on the bottom and N-719 sensitized NRs based DSSC on the top, followed by a series connecting them with electric wires.

For SC II, the top cell is the same as the bottom cell that are both based on $\mathrm{TiO}_{2}$ NRs, as shown in the Figure 3A. The top cell is sensitized by N-719, while bottom cell is sensitized by N749. In order to avoid parallel connection of the three cells, a thin layer of PMMA was spin coated on the Ti foil, and then a $50 \mathrm{~nm}$ platinum layer was sputtered on the PMMA, which was used as the counter electrode of the bottom cell.

Assembly of LIB Part. The LIB part on the other side of the $\mathrm{Ti}$ foil was composed of three components: anode, separator, and cathode. The anode was aligned $\mathrm{TiO}_{2} \mathrm{NTs}$ that are directly grown on the backside of the $\mathrm{Ti}$ foil. The polyethylene (PE) separator was located above the $\mathrm{TiO}_{2} \mathrm{NTs}$ as the separator. The cathode was a mixture of $\mathrm{LiCoO}_{2} /$ conductive carbon/binder mixtures on an aluminum foil. After placing the cathode on the separator, the system was filled with electrolyte ( $1 \mathrm{M} \mathrm{LiPF}_{6}$ in 1:1 ethylene carbonate:dimethyl carbonate) and finally sealed with epoxy. The structures are schematically shown in Figure 1A.

Performance of the Power Pack. The solar cell was irradiated using a solar simulator (500 W Model 91160, Newport) with an AM 1.5 spectrum distribution calibrated against a NREL reference cell to accurately simulate a full-sun intensity $\left.(100 \mathrm{~mW} \mathrm{~cm})^{-2}\right)$. The power pack is solar-illumination charged and galvanostatically discharged between 0.75 and $3 \mathrm{~V}$ on a program-controlled test system.

Figure $3 \mathrm{~B}, \mathrm{C}$ is the photocurrent density-voltage curves of the SC I and the SC II, showing the open circuit voltage $V_{\mathrm{OC}}$, short-circuit current density $J_{\mathrm{SC}}$, fill factor $\mathrm{FF}$, and energy conversion efficiency $\eta=\mathrm{FF} \cdot V_{\mathrm{OC}} \cdot J_{\mathrm{SC}} / P_{\text {in }}$, where $P_{\text {in }}$ is the incident light power density. For the three tandem DSSCs, sun light first irradiates on the N-719 sensitized top cells and then irradiates on the N-749 sensitized buttom cells. The $V_{\text {oc }}$ of the top cells for both cells are higher than that of the bottom cells which can be ascribed to the local light intensity in the bottom cells is lower than that in the top cells. The total $V_{\text {oc }}$ value of the tandem DSSCs is 1.36 and $1.19 \mathrm{~V}$, nearly equivalent to the sum of individual $V_{\text {oc }}$ values of the top and bottom cells. Thus, cosensitized DSSCs not only can harvest broader light but also can effectively enhance the $V_{\text {oc }}$ without increasing the active area. It is worth mentioning that the thickness of $\mathrm{TiO}_{2}$ films plays a significant role on the performance of the tandem cells due to it directly influences the light transmittance. We note that the thickness of the $\mathrm{TiO}_{2}$ films on the top cells should be smaller than those on the bottom cells.

Figure 4A shows the solar-charge/discharge cycling performances of the integrated power pack, the DSSCs part and LIB part keeped connecting during all the charge and discharge processes. At the very beginning, the device is at a discharged 


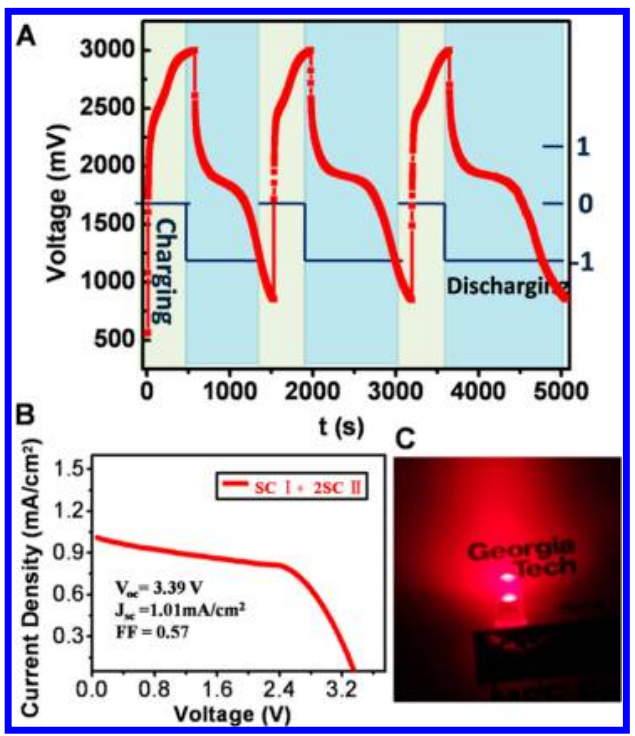

Figure 4. (A) Three discharge/charge cycling performances of the hybrid DSSCs and lithium ion battery. The DSSCs are irradiated using a solar simulator in a full-sun intensity, the device was discharged under a discharge current of $100 \mu \mathrm{A}$. (B) $J-V$ curves of the DSSC with three tandem cells (SC I and 2SC II) connected in series, illumination conditions: $1000 \mathrm{~W} \cdot \mathrm{m}^{-2}$ AM $1.5 \mathrm{G}$. (C) The light-emitting diode (LED) powered by using the storage energy.

state with $\mathrm{LiCoO}_{2}$ as the positive electrode (cathode) material and $\mathrm{TiO}_{2} \mathrm{NTs}$ as the negative electrode (anode). When the series-connection DSSCs are irradiated using a full-sun intensity solar simulator, the voltage of the power pack increases from $550 \mathrm{mV}$ to $2996 \mathrm{mV}$ in $440 \mathrm{~s}$. After the solarcharging process, the power pack was discharged back to 750 $\mathrm{mV}$ in about $1400 \mathrm{~s}$ under a discharge current density of 100 $\mu \mathrm{A}$. Thus, the stored electric capacity of the power pack was about $33.89 \mu \mathrm{Ah}$. The performances of the three series connection DSSCs are shown in the Figure 4B, 3.39 V opencircuit voltage and $1.01 \mathrm{~mA} / \mathrm{cm}^{2}$ short-circuit current can be obtained under solar irradiation. The stored electrochemical energy was used to drive a commercial red LED (Figure 4C, Avago Technologies US Inc., HLMP-1700). The conversion efficiency $\eta$ of the entire cell is $\sim 0.82 \%\left(\eta=\int V I \mathrm{~d} t /\left(P_{\text {in }} t_{1} \eta_{\mathrm{sc}}\right)\right)$, and the efficiency for energy storage is $41 \%$. It is interesting that the discharging processes become longer and longer for this integrated device, which may be due to the increase of the internal resistance of DSSCs after continuous working.

In summary, a new integrated power pack consisting of a DSSC and a LIB is fabricated based on double-sided $\mathrm{TiO}_{2}$ NTs. The upper part of the device is composed of three tandem DSSCs based on $\mathrm{TiO}_{2}$ NRs and NTs, which effectively harvest solar energy with high voltage output $(3.39 \mathrm{~V}$ open-circuit voltage and $1.01 \mathrm{~mA} / \mathrm{cm}^{2}$ short-circuit current). The lower region is a $\mathrm{LIB}$ part based on $\mathrm{TiO}_{2} \mathrm{NTs}$ and $\mathrm{LiCoO}_{2}$, which store electrochemical energy. The DSSCs and LIBs share the same Ti substrate. When the power pack was irradiated using a full-sun intensity solar simulator, the voltage increased to 2.996 $\mathrm{V}$ in less than $8 \mathrm{~min}$, and the discharge capacity is about 38.89 $\mu \mathrm{Ah}$ under a discharge current density of $100 \mu \mathrm{A}$. The total energy and storage efficiency of the system is up to $0.82 \%$. The present results suggest that such a flexible, ultrathin structure, and lightweight of the integrated power pack has potential applications in many fields where there are needs for portable and small size electronics.

\section{ASSOCIATED CONTENT}

\section{S Supporting Information}

The XRD patterns of the as-synthesized $\mathrm{TiO}_{2}$ nanotube arrays and $\mathrm{TiO}_{2}$ nanorod arrays and the UV-vis spectra of dye N-719 and N-749 in absolute ethyl alcohol solution. This material is available free of charge via the Internet at http://pubs.acs.org.

\section{AUTHOR INFORMATION}

\section{Corresponding Author}

*E-mail: zhong.wang@mse.gatech.edu

\section{Author Contributions}

${ }^{\perp}$ These authors contributed equally.

Notes

The authors declare no competing financial interest.

\section{ACKNOWLEDGMENTS}

Thanks for the support of NSF, BES, and DOE. W.X.G. thanks the support from the Chinese Scholars Councils.

\section{REFERENCES}

(1) Oregan, B.; Gratzel, M. Nature 1991, 353 (6346), 737-740.

(2) Tian, B. Z.; Zheng, X. L.; Kempa, T. J.; Fang, Y.; Yu, N. F.; Yu, G.

H.; Huang, J. L.; Lieber, C. M. Nature 2007, 449 (7164), 885-U8.

(3) Wang, Z. L.; Song, J. H. Science 2006, 312 (5771), 242-246.

(4) Zhu, J.; Cui, Y. Nat. Mater. 2010, 9 (3), 183-184.

(5) Law, M.; Greene, L. E.; Johnson, J. C.; Saykally, R; Yang, P. D. Nat. Mater. 2005, 4 (6), 455-459.

(6) Arico, A. S.; Bruce, P.; Scrosati, B.; Tarascon, J. M.; Van Schalkwijk, W. Nat. Mater. 2005, 4 (5), 366-377.

(7) Poudel, B.; Hao, Q.; Ma, Y.; Lan, Y. C.; Minnich, A.; Yu, B.; Yan, X. A.; Wang, D. Z.; Muto, A.; Vashaee, D.; Chen, X. Y.; Liu, J. M.; Dresselhaus, M. S.; Chen, G.; Ren, Z. F. Science 2008, 320 (5876), 634-638.

(8) Shao, Z. P.; Haile, S. M.; Ahn, J.; Ronney, P. D.; Zhan, Z. L.; Barnett, S. A. Nature 2005, 435 (7043), 795-798.

(9) Qin, Y.; Wang, X.; Wang, Z. L. Nature 2009, 457 (7227), 340340.

(10) Varghese, O. K.; Paulose, M.; Grimes, C. A. Nat. Nanotechnol. 2009, 4 (9), 592-597.

(11) Chan, C. K.; Peng, H. L.; Liu, G.; Mcllwrath, K.; Zhang, X. F.; Huggins, R. A.; Cui, Y. Nat. Nanotechnol. 2008, 3 (1), 31-35.

(12) Idota, Y.; Kubota, T.; Matsufuji, A.; Maekawa, Y.; Miyasaka, T. Science 1997, 276 (5317), 1395-1397.

(13) Tarascon, J. M.; Armand, M. Nature 2001, 414 (6861), 359367.

(14) Poizot, P.; Laruelle, S.; Grugeon, S.; Dupont, L.; Tarascon, J. M. Nature 2000, 407 (6803), 496-499.

(15) Jiang, J. A.; Li, Y. Y.; Liu, J. P.; Huang, X. T. Nanoscale 2011, 3 (1), $45-58$.

(16) Raffaelle, R. P.; Underwood, J.; Scheiman, D.; Cowen, J.; Jenkins, P.; Hepp, A. F.; Harris, J.; Wilt, D. M. Conf. Rec. IEEE Photovoltaic Spec. Conf. 2000, 1370-1373.

(17) He, Y. T.; Wang, L. IEEE Int Power Elec 2009, 1242-1245.

(18) Zhou, Y. K.; Cao, L.; Zhang, F. B.; He, B. L.; Li, H. L. J. Electrochem. Soc. 2003, 150 (9), A1246-A1249.

(19) Ye, M. D.; Xin, X. K.; Lin, C. J.; Lin, Z. Q. Nano Lett. 2011, 11 (8), 3214-3220.

(20) Roy, P.; Kim, D.; Lee, K.; Spiecker, E.; Schmuki, P. Nanoscale 2011, 3 (12), 5180-5180.

(21) Liu, B.; Aydil, E. S. J. Am. Chem. Soc. 2009, 131 (11), 39853990.

(22) Shankar, K.; Mor, G. K.; Prakasam, H. E.; Yoriya, S.; Paulose, M.; Varghese, O. K.; Grimes, C. A. Nanotechnology 2007, 18 (6), 065707. 